\title{
Performance Analysis of FICA and PIFA Antenna with LNA Co-Design
}

\author{
Nischal Kumar Das \\ School of ICT \\ Gautam Buddha University \\ Greater Noida,India
}

\author{
Shakti Tripathi \\ School of ICT \\ Gautam Buddha University \\ Greater Noida,India
}

\author{
Navaid Z. Rizvi \\ School of ICT \\ Gautam Buddha University \\ Greater Noida,India
}

\begin{abstract}
Smart Dust Wireless Sensor Networks (SDWSNs), which are the members of Wireless Sensor Network (WSN) family play a vital role as the requirements on communication node sizes and power consumption have become more stringent. Several low volume antennas have been designed and Low Noise Amplifier (LNA) and antenna co-designs have been devised to increase the level of design integration and reduce the receiver noise. In this paper we simulate two such antennas namely F Inverted Compact Antenna (FICA) and Planar Inverted $\mathrm{F}$ Antenna (PIFA) and compare their results to obtain the design with better performance.
\end{abstract}

\section{Keywords}

SDWSN, FICA, PIFA, ESA.

\section{INTRODUCTION}

SDWSNs require a high level of design integration as they comprise of a large number of nodes. Electrically Small Antennas (ESAs) provide a solution to this problem. Two such antennas are FICA and PIFA which have been discussed in this paper. Another requirement of SDWSN is decrement in receiver power consumption and noise. To address this issue LNA has been co-designed with antenna. This LNA is discussed ahead. Further, in this paper FICA and PIFA have been co-designed with LNA. Then their performance has been simulated and their results have been compared.

\section{F INVERTED COMPACT ANTENNA}

It is one of the novel low profile ESAs. It has a very limited ground plane size and the total volume is also very low. This is its major advantage. FICA comprises of two parts, the tapping loop and the helix matching structure. The circuit of FICA shown in Figure 1 has five lumped components. $\mathrm{L}_{\mathrm{ST}}$ is the inductance of the shorting stub. R1 is the radiation resistance and LFD represents the inductance of the feeding pin. They constitute the tapping loop. The second part consists of R2 and X2. Here R2 represents ohmic loss of ground plane and antenna. The antenna is actually designed as a short monopole over a ground plane and it has a helical impedance matching transmission line. The radiation efficiency of this FICA is around $48.5 \%$, and if required it can be scaled to lower or higher frequency bands.

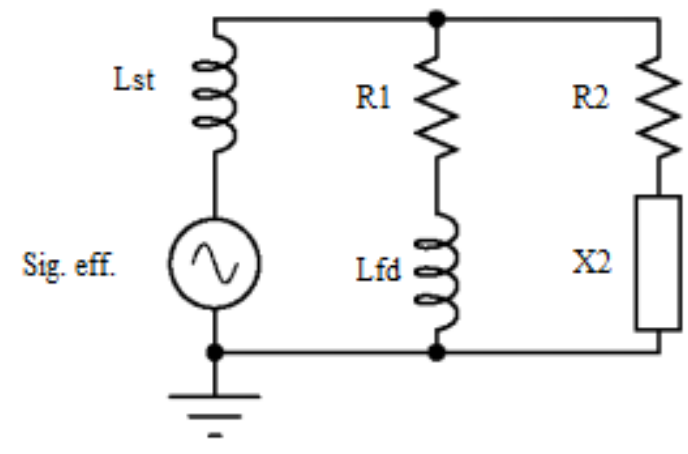

Fig 1: Circuit Model of FICA [B. Yang, 10]

\section{PLANAR INVERTED F ANTENNA}

PIFA is a combination of the inverted $F$ antenna and the patch antenna. It has a wider bandwidth due to the radiating patch. PIFA is a type of patch antenna which is commonly used in cellular phone which have built-in antennas. At quarter wavelength PIFA is resonant. Its design resembles an inverted F. It has been derived from half patch antenna. The length of the shorting plane is reduced which in turn reduces the resonant frequency.

The equivalent circuit comprises of inductance L1, capacitance $\mathrm{C} 1$ and conductance G1. N1 represents the electromagnetic coupling.

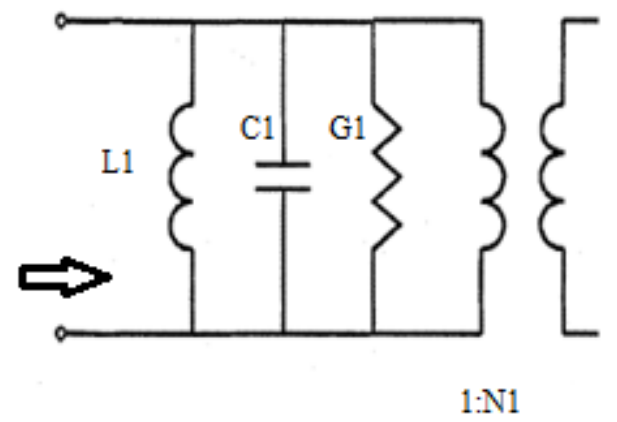

Fig.2. Circuit Model of PIFA [Del Barrio S.C., 11]

\section{LOW NOISE AMPLIFIER (LNA)}

It is the initial stage of almost all the receiver architectures. It decides the noise level of the system. LNA consumes power to suppress noise and provide gain and linearity. So, active and passive component optimization techniques are employed to develop an efficient high voltage gain cascade LNA. These electronic amplifiers are used for the amplification of very weak signals which are captured by an antenna. Its location is generally based near the detection device in order to reduce 
the losses occurring in the feed line. The purpose of using LNA is to minimize the effect of noise from the following stages of the receiver with the help of gain provided by the LNA. For low noise and high amplification transistors such as JFETs are used.

\section{ANTENNA AND LNA CO-DESIGN}

The input matching network of the LNA provides optimum admittance without introducing any extra noise sources in the input signal path, ideally. The bonding wires and the bonding pads appearing at the antenna-LNA interface are also included in the co-design when the antenna and the LNA are integrated. This co-design increases the antenna and system integration and saves chip area. Two circuits have been codesigned in this work using $120 \mathrm{~nm}$ technology.

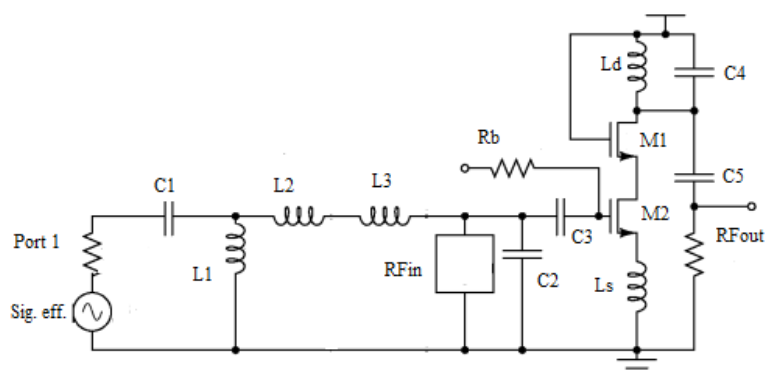

Fig.3. FICA circuit with co-designed LNA network [B. Yang, 10]

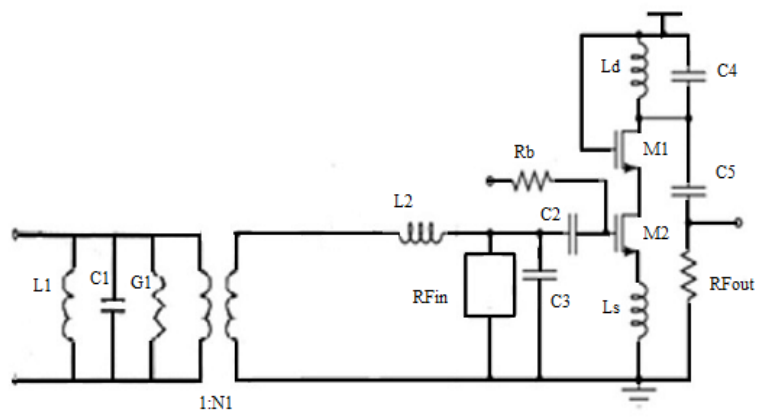

Fig.4. PIFA circuit with co-designed LNA network [Del Barrio S.C., 11] [B. Yang, 10]

\section{SIMULATION AND RESULTS}

FICA and PIFA-LNA co-designs have been implemented using $120 \mathrm{~nm}$ technology. The values of s-parameters, noise figure and noise sensitivity factor have been obtained from the designs and then compared.

Shown next is the schematic diagram of FICA-LNA co-design implemented on CADENCE VIRTUOSO. Then all the four sparameters have been obtained for this two port network. Further its immunity to noise is observed. This is done by computing the noise figure and noise sensitivity factor of the co-design.

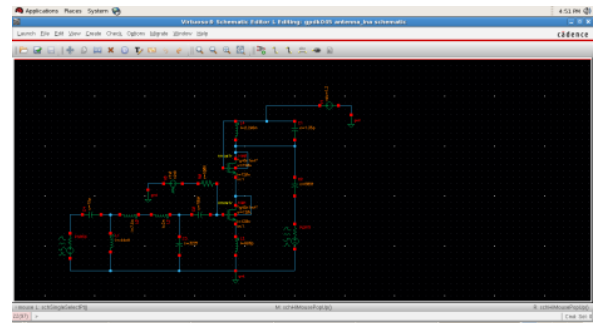

Fig.5. FICA schematic with LNA Co-Design

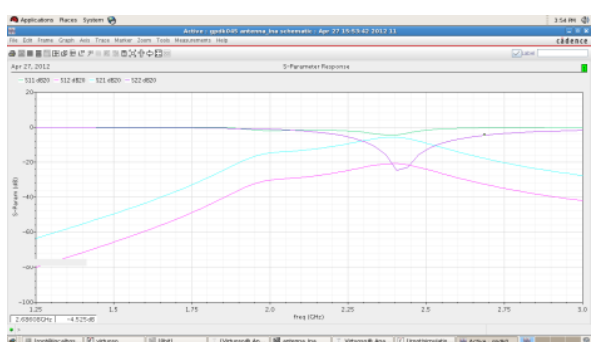

Fig.6. s-parameters of FICA

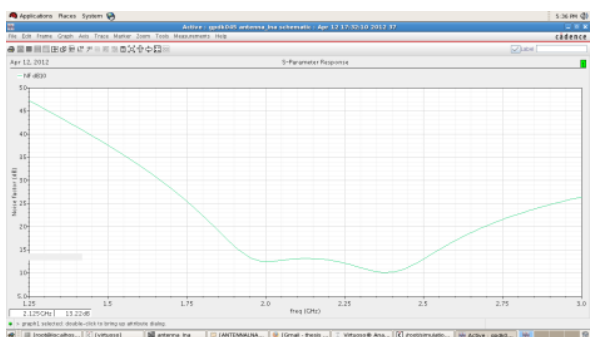

Fig.7. NF of FICA

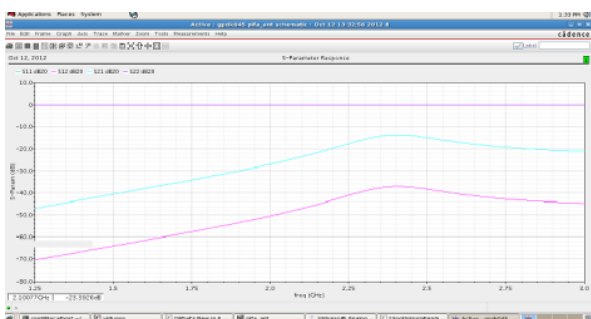

Fig.8. Rn of FICA

The figure shown below is the schematic diagram of the PIFA-LNA co-design. This network is then used to compute the desired parameters which help in judging the performance of the design and its immunity to noise.

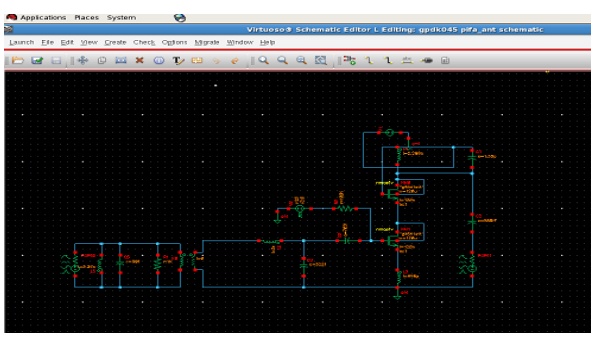

Fig.9. Schematic of PIFA- LNA Co-design 


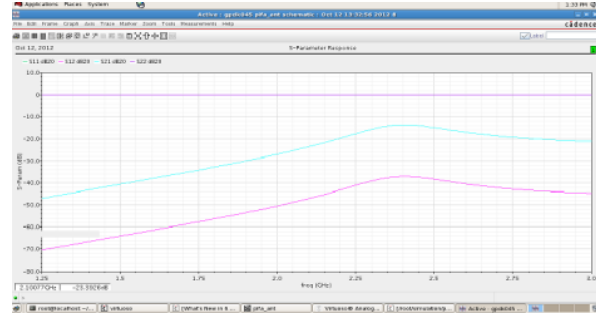

Fig.10. s-parameters of PIFA

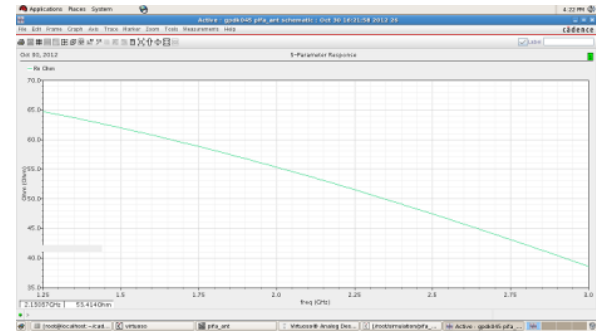

Fig.11. Rn of PIFA

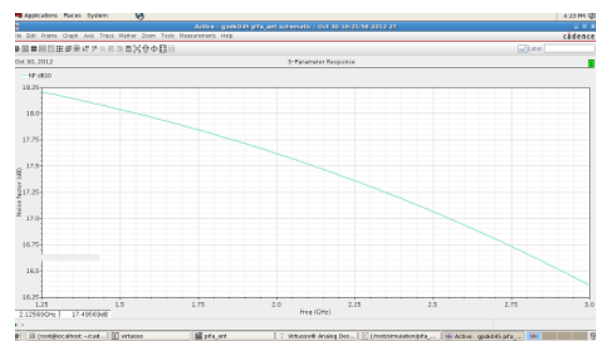

Fig.12. NF of PIFA

Table 1. Comparison table

\begin{tabular}{|c|c|c|}
\hline Parameters & FICA(120nm) & PIFA(120nm) \\
\hline $\mathrm{s}_{11(\max )}$ & $\begin{array}{l}-665.3 \mu \mathrm{db} \text { at } \\
1.25165 \mathrm{GHz}\end{array}$ & $\begin{array}{l}-32.12 \mathrm{udb} \text { at } \\
1.25206 \mathrm{GHz}\end{array}$ \\
\hline $\mathrm{s}_{11(\min )}$ & $\begin{array}{l}-4.396 \mathrm{db} \text { at } 2.37238 \\
\mathrm{GHz}\end{array}$ & $\begin{array}{l}-57.826 \mathrm{mdb} \text { at } \\
2.405 \mathrm{GHz}\end{array}$ \\
\hline $\mathrm{s}_{12(\max )}$ & $\begin{array}{l}-20.854 \mathrm{db} \text { at } \\
2.41089 \mathrm{GHz}\end{array}$ & $\begin{array}{l}-36.905 \mathrm{db} \text { at } \\
2.4011 \mathrm{GHz}\end{array}$ \\
\hline $\mathrm{s}_{12(\mathrm{~min})}$ & $\begin{array}{l}-79.914 \mathrm{db} \text { at } \\
1.25167 \mathrm{GHz}\end{array}$ & $\begin{array}{l}-70.275 \mathrm{db} \text { at } \\
1.25069 \mathrm{GHz}\end{array}$ \\
\hline $\mathrm{S}_{21(\max )}$ & $\begin{array}{l}-5.7156 \mathrm{db} \text { at } \\
2.38833 \mathrm{GHz}\end{array}$ & $\begin{array}{l}-13.45307 \mathrm{db} \text { at } \\
2.4007 \mathrm{GHz}\end{array}$ \\
\hline $\mathrm{S}_{21(\mathrm{~min})}$ & $\begin{array}{l}-63.387 \mathrm{db} \text { at } \\
1.25167 \mathrm{GHz}\end{array}$ & $\begin{array}{l}-46.82116 \mathrm{db} \text { at } \\
1.25069 \mathrm{GHz}\end{array}$ \\
\hline $\mathrm{S}_{22(\max )}$ & $\begin{array}{l}-38.0892 \mathrm{mdb} \text { at } \\
1.25167 \mathrm{GHz}\end{array}$ & $\begin{array}{l}24.161 \mathrm{mdb} \text { at } \\
1.25651 \mathrm{GHz}\end{array}$ \\
\hline $\mathrm{S}_{22(\mathrm{~min})}$ & $\begin{array}{l}-24.5454 \mathrm{mdb} \text { at } \\
2.40476 \mathrm{GHz}\end{array}$ & $\begin{array}{l}-44.02 \mathrm{mdb} \text { at } \\
2.40437 \mathrm{GHz}\end{array}$ \\
\hline $\mathrm{R}_{\mathrm{n}(\max )}$ & $\begin{array}{l}51.0523 \mathrm{~K} \Omega \text { at } \\
1.25172 \mathrm{GHz}\end{array}$ & $\begin{array}{l}64.765 \Omega \text { at } \\
1.25068 \mathrm{GHz}\end{array}$ \\
\hline $\mathrm{R}_{\mathrm{n}(\min )}$ & $578.237 \mathrm{~m} \Omega$ at & $38.617 \Omega$ at $3 \mathrm{GHz}$ \\
\hline
\end{tabular}

\begin{tabular}{|l|l|l|}
\hline & $3.405 \mathrm{GHz}$ & \\
\hline $\mathrm{NF}_{(\max )}$ & $47.07 \mathrm{db}$ at & $18.20973 \mathrm{db}$ at \\
& $1.25486 \mathrm{GHz}$ & $1.25069 \mathrm{GHz}$ \\
& & \\
\hline $\mathrm{NF}_{(\min )}$ & $10.23 \mathrm{db}$ at & $16.36433 \mathrm{db}$ at \\
& $2.39451 \mathrm{GHz}$ & $3 \mathrm{GHz}$ \\
\hline
\end{tabular}

The results clearly show that FICA exhibits lower reflection coefficients and higher voltage gains as compared to PIFA. Another major parameter that may alter the performance of a network is noise. The results show that FICA is more immune to noise.

\section{CONCLUSION}

These plots and tables show the values for s-parameters, noise figure and noise sensitivity factor for both the designs. $S_{11}$ gives the values for input port reflection coefficient. The input port reflection coefficients are lower for FICA as compared to PIFA. $S_{12}$ represents the reverse voltage gain. The value of reverse voltage gain is higher for FICA. FICA gives better result as compared to PIFA. $S_{22}$ gives the value of output port reflection coefficient. Its value is lower for FICA when compared with PIFA. The plots show that FICA is less sensitive to noise as compared to the PIFA design. FICA yields better results for noise figure as its value for noise figure is lower as compared to that of PIFA. Thus it is concluded that the FICA-LNA co-design yields better performance results when compared with PIFA-LNA codesign.

\section{REFERENCES}

[1] B.W. Cook, S. Lanzisera, and K. S. J. Pister, "SoC issues for RF smart dust," Proceedings of the IEEE, vol. 94, no. 6, pp. 1177 -1196, Jun. 2006.

[2] J. M. Kahn, R. H. Katz, and K. S. J. Pister, "Next century challenges: mobile networking for "smart dust", International Conference on Mobile Computing and Networking (MOBICOM99), pp. 271-278, Seattle.

[3] A-S. Porret, T. Melly, D. Python, C. C. Enz, and E. A. Vittoz, "An ultralow-power UHF transceiver integrated in a standard digital CMOS process: architecture and receiver," IEEE J. Solid State Circuits, vol. 36, no.3, pp. 452 - 466, Mar. 2001

[4] J. M. Rabaey, J. Ammer, T. Karalar, S. Li, B. Otis, M. Shetts, and T. Tuan, "Pico Radios for wireless sensor networks: the next challenge in ultra-low power design," IEEE Int. Solid-State Circuits Conf. Dig. Tech. Papers (ISSCC2002), Feb. 2002.

[5] J.Rabaey, J. Ammer, B. Otis, F. Burhardt, Y. H. Chee, N. Pletcher, M. Sheets, and H. Qin, "Ultra-low-power design - the roadmap to disappearing electronics and ambient intelligence," IEEE Circuits \& Devices Magazine, pp. 23- 29, Jul./Aug. 2006.

[6] D. K. Shaeffer and t. H. Lee, "A 1.5-V, 1.5-GHz CMOS low noise amplifier," IEEE J. Solid State Circuits, vol. 32, no.5, pp. 745-759, May. 1997.

[7] A.Wheeler, "Fundamental limitations of small antennas," Proc. Of IRE, vol. 35, no. 12, pp. 1479-1487, Dec. 1947. 
[8] B. Yang, F. Vanin, C.-C. Shen, X. Shao, Q. Balzano, N.Goldsman, and C. Davis, "A Low Profile 916 MHz FInverted Compact Antenna (FICA) for Wireless Sensor Networks," AP-S International Symposium, 2007, Honolulu, Hawaii, June, 2007.

[9] B. Yang, X. Shao, Q. Balzano, N. Goldsman, and G Metze, "916vMHz F-Inverted Compact Antenna (FICA) for Highly IntegratedvTransceivers," Antennas and Wireless Propagation Letters, vol.8, pp.181-184, 2009.
[10] Ultra small antenna and low power receiver for smart dust wireless sensor networks by B.Yang, Doctor of Philosophy, Department of Electrical and Computer Engineering, Ph.D. Thesis, 2009.

[11] Del Barrio, S.C., Pelosi, M., Franek, O., Pedersen, G.F. ,"Equivalent Circuit of a High Q Tunable PIFA",

Vehicular Technology Conference (VTC Fall), 2011 IEEE Digital Object Identifier,Publication Year: 2011 , Page(s): $1-4$. 